\title{
Bioequivalence Study of Two Formulations Containing Lurasidone 80 mg Tablets in Healthy Colombian Volunteers
}

\author{
Vargas $\mathbf{M}^{1 *}$, and Villarraga $\mathrm{EA}^{2}$ \\ ${ }^{1}$ Pharmacology Unit University of la Sabana, Bogotá-Colombia \\ ${ }^{2}$ Doctor, Pharmacologist, Medical Study Coordinator, Bogotá-Colombia
}

\begin{abstract}
This is a pharmacokinetic study of two formulations containing Lurasidone $80 \mathrm{mg}$, with the aim to compare the Bioavailability between the Test product (Lurasidone made by Laboratorios Lafrancol S.A, Colombia) and the Reference product (Latuda ${ }^{\circledR}$ made by Laboratorio Sunovion) in order to declare the Bioequivalence between both formulations. For this, an open-label, two period and two sequences previously randomized, crossover study in 24 healthy volunteers was developed, with a single $80 \mathrm{mg}$ dose in fasting conditions, a washout period of 15 days and 12 plasma samples collection between 0 and $72 \mathrm{~h}$. The analytical method used was HPLC. The $90 \%$ confidence interval for the $\mathrm{C}_{\max }$ parameter was between 96.4-103.7 with a 103.2 ratio; for the $\mathrm{AUC}_{0 . \mathrm{t}}$ parameter the $90 \% \mathrm{Cl}$ it is between 86.8-107.4 with a 98.2 ratio, and for the $\mathrm{AUC}_{0-\infty}$ the $90 \% \mathrm{Cl}$ was found to be between 90.4-108.9 with a 99.2 ratio. According to the European and FDA guidelines for Bioequivalence research, the confidence interval is within the allowed ranges for the Bioequivalence declaration and interchangeability of the Lafrancol S.A. product with the Reference product.
\end{abstract}

Keywords: Bioequivalence; Lurasidone; Antidepressant; Pharmacokinetics

\section{Introduction}

Lurasidone is indicated for the treatment of adult patients with major depressive episodes associated with bipolar I disorder (bipolar depression) [1]. Bipolar depression is characterized by debilitating mood changes, by one or more manic or mixed episodes; often, individuals also experience at least one major depressive episode.

The objective of this study was to establish the Bioequivalence of two formulations containing Luirasidone $80 \mathrm{mg}$ tablets by comparing its bioavailability after a single dose between the Test product produced by Lafrancol S.A. (Colombia) and the Reference product, Latuda, produced by Sunovion.

\section{Materials and Methods}

\section{Study formulations}

Test drug: Lurasidone $80 \mathrm{mg}$ tablets, manufactured in Colombia by Lafrancol S.A. Lot 4 A 8517.

Reference drug: Latuda Lurasidone $80 \mathrm{mg}$ tablets, manufactured and distributed by Sunovion Lot 3119821.

Subjects: 24 healthy non-smoking subjects from both genders, 12 female and 12 male, aged between 20 and 47 years old with a Body Mass Index (BMI) of $19.5-28.5 \mathrm{~kg} / \mathrm{m}^{2}$, completed the study (Table 1).

All volunteers were assessed with a medical examination and laboratory tests before the clinical phase to confirm their health status. Alcoholism history, preexistent diseases compromising liver or kidney function, blood dyscrasia or proteinuria were considered as exclusion factors.

\begin{tabular}{|c|c|}
\hline Demographic Variable & Obtained Mean $(\mathbf{n = 2 4})$ \\
\hline Age (years) & $323 \pm 9.0$ \\
\hline Height $(\mathrm{cm})$ & $167 \pm 9.6$ \\
\hline Weight $(\mathrm{kg})$ & $65 \pm 10.4$ \\
\hline BMI $\left(\mathrm{kg} / \mathrm{m}^{2}\right)$ & $23.5 \pm 2.8$ \\
\hline
\end{tabular}

Table 1: Demographic data of volunteers included in the pharmacokinetic and statistical analysis.
Medical examinations and clinical laboratory tests: Performed clinical laboratory tests included complete blood count, total and direct bilirubin, creatinine, glycaemia, total protein, complete urinalysis, HIV ELISA test, antibodies against hepatitis B and C, electrocardiogram and blood pregnancy test for women.

Informed consent process: The protocol and the informed consent form were authorized by the La Sabana University Clinical Research Ethics Committee (CREC) which is ruled by the legal and ethical guidelines of the resolutions 008430 of 1993 and 002378 of 2008 of the Ministry of Social Protection (Colombia), World Conference on Harmonization for Good Clinical Practice of Institutions Conducting Investigation in Human Subjects and by the World Medical Assembly principles published in the Declaration of Helsinki, last review in 2008 [2]

Volunteers were explained in detail about the study, emphasizing on the type of medication to be used, dose, potential drug adverse reactions, blood volume to be collected at each study phase, the material to be used to collect such samples, the staff in charge of sampling and monitoring, diet restrictions to comply with, and all the information they requested to freely decide on their participation in the study. Subsequently, each one of them signed an informed consent form.

Study design: A randomized, open-label, two periods, two sequences; crossover design was used with a 15 days washout period between each period. Three days before each period initiation, volunteers must refrain from medications, alcohol and any food

*Corresponding author: Vargas M, Dentist, Pharmacologist, Scientific Director Pharmacology Unit University of la Sabana, Bogotá-Colombia, Tel: 861 5555; E-mail: mauricio.vargas@unisabana.edu.co

Received July 21, 2016; Accepted August 09, 2016; Published August 16, 2016

Citation: Vargas M, Villarraga EA(2016) Bioequivalence Study of Two Formulations Containing Lurasidone $80 \mathrm{mg}$ Tablets in Healthy Colombian Volunteers. J Bioequiv Availab 8: 220-223. doi:10.4172/jbb.1000299

Copyright: $\odot 2016$ Vargas M, et al. This is an open-access article distributed under the terms of the Creative Commons Attribution License, which permits unrestricted use, distribution, and reproduction in any medium, provided the original author and source are credited. 
Citation: Vargas M, Villarraga EA (2016) Bioequivalence Study of Two Formulations Containing Lurasidone 80 mg Tablets in Healthy Colombian Volunteers. J Bioequiv Availab 8: 220-223. doi:10.4172/jbb.1000299

or beverage containing methylxanthines. These restrictions were maintained during the entire sampling period. All volunteers were randomized to be allocated to the treatment sequence.

Drug administration: Volunteers had 10 hours fasting prior administration of the drug, which was given with $200 \mathrm{~mL}$ of water at doses of Lurasidone $80 \mathrm{mg}$ [3] (i.e., 1 tablet of $80 \mathrm{mg}$ ) to each volunteer, and two hours later, each volunteer was given a standardized food. During hospital stay, they received three full meals (breakfast, lunch and dinner) and two snacks (one in the morning and one in the afternoon). These are shown in Table 2.

The sampling team was comprised by a physician and one registered nurse. Using Vacutainer, a blood sample was obtained by venipuncture in the superior limb immediately prior to administering the medication. Such sample was called 'zero time point sample'. All volunteers received both the Test and Reference product based on randomization and 12 blood venous samples were collected according to the following time points: $0,1,2,2.5,3,4,6,8,12,24,48$ and $72 \mathrm{~h}$. Samples were labeled for identification and centrifuged at $3000 \mathrm{rpm}$ for $30 \mathrm{~min}$. Plasma was transferred to a previously labeled tube and frozen at $-20^{\circ} \mathrm{C}$ for later analysis. After an 15-day washout period, administration was repeated completing the second study period.
Validation of analytical method: The bioanalytical method employed for Lurasidone quantification in plasma was highperformance liquid chromatography with UV detection (HPLC-UV). For the preparation of the sample were taken $2.0 \mathrm{~mL}$ of charged plasma, were added $5 \mathrm{~mL}$ of Ether Diethyl, then applied 15 minutes vortexed, centrifuged for 1 minute, then taking the supernatant and evaporate it with nitrogen, reconstituted with $1.0 \mathrm{~mL}$ of mobile phase and filtered through $0.45 \mu \mathrm{m}$ taken to a vial $[4,5]$.

Analyte separation was Achieved With An Symmetry Shield" RP18 5 microns, $3.9 \times 150 \mathrm{~mm}$ Column, at a temperature of $40^{\circ} \mathrm{C}$ Employing an HPLC SHIMADZU LC2010, elution was Performed with a mobile phase Comprised by buffer solution: (Acetonitrile: Buffer phosphate monobasic $10 \mathrm{mM}$ potassium with triethylamine (1:1000), (32:68)), at a constant flow rate of $1.0 \mathrm{~mL} / \mathrm{min}$. Total run time was $10 \mathrm{~min}$ and the limit of quantitation of $5 \mathrm{ng} / \mathrm{ce} / \mathrm{mL}$.

Pharmacokinetic analysis: The pharmacokinetic analysis was performed using WinNonlin 5.3 (Pharsight Corporation, Cary USA) software, by means of a non-compartmental analysis. Peak concentration $\left(\mathrm{C}_{\max }\right)$ and time to peak concentration $\left(\mathrm{t}_{\max }\right)$ were directly obtained from results of plasma concentrations, as currently recommended by the FDA [6] and the European Medicines Agency

\begin{tabular}{|c|c|c|c|c|c|c|c|c|c|c|}
\hline \multicolumn{11}{|c|}{ Universidad de la Sabana clinic Content of Mean Calories and Nutrients Evaluation Pattern List Normal. Semi-Bland. Low-Salt Diet and/or Pattern } \\
\hline Nutrients & Portion & Quantity & K. & Prot. & Fat & Cholesterol & Cho & Fiber & Calcium & Phosphorus \\
\hline Type of Food & Served & g or c.c. & cal & g & g & mg & g & g & mg & mg \\
\hline \multicolumn{11}{|c|}{ Break Fast } \\
\hline Fruit Juice & $200 \mathrm{cc}$ & 60.0 & 22.2 & 0.5 & 0.1 & 0.0 & 5.6 & 0.5 & 9.7 & 11.6 \\
\hline Hot Milk Beverage & $180 \mathrm{cc}$ & 180.0 & - & - & - & - & - & - & - & - \\
\hline Milk $(100 \%)$ & $180 \mathrm{cc}$ & 180.0 & 90.0 & 6.1 & 4.5 & 25.2 & 7.0 & 0.0 & 216.0 & 171.0 \\
\hline BEV (1) powder preparation & $10 \mathrm{~g}$ & 10.0 & 40.3 & 0.9 & 0.9 & 0.0 & 7.3 & 0.1 & 22.8 & 27.2 \\
\hline Protein (1) egg cheese & $80 \mathrm{~g}$ & 80.0 & 141.4 & 14.2 & 7.9 & 139.8 & 1.9 & 0.0 & 118.4 & 153.4 \\
\hline Carbohydrates (2) bread/subst. & $60 \mathrm{~g}$ & 60.0 & 195.2 & 5.0 & 4.9 & 0.0 & 33.8 & 0.5 & 40.0 & 69.4 \\
\hline Accompaniments & - & - & - & - & - & - & - & - & - & - \\
\hline Butter & $10 \mathrm{~g}$ & 10.0 & 73.2 & 0.1 & 8.2 & 21.9 & 0.1 & 0.0 & 2.2 & 2.0 \\
\hline Jam & $8 \mathrm{~g}$ & 8.0 & 22.1 & 0.0 & 0.0 & 0.0 & 5.6 & 0.0 & 1.0 & 1.0 \\
\hline Total Breakfast & - & - & 584.3 & 26.9 & 26.5 & 186.9 & 61.4 & 1.2 & 410.1 & 435.6 \\
\hline \multicolumn{11}{|c|}{ Lunch } \\
\hline Fruit Juice & $200 \mathrm{cc}$ & 60.0 & 22.2 & 0.5 & 0.1 & 0.0 & 5.6 & 0.5 & 9.7 & 11.6 \\
\hline Soup or Cream & $200 \mathrm{cc}$ & 200.0 & - & - & - & - & - & - & - & - \\
\hline Carbohydrates (5) tub. plant root & $50 \mathrm{~g}$ & 50.0 & 58.3 & 0.7 & 0.1 & 0.0 & 14.5 & 0.5 & 5.9 & 20.5 \\
\hline Cooked Vegetables & $40 \mathrm{~g}$ & 40.0 & 14.4 & 1.0 & 0.1 & 0.0 & 2.7 & 0.5 & 30.7 & 24.1 \\
\hline Cereal Soup & $25 \mathrm{~g}$ & 25.0 & 85.6 & 2.8 & 0.5 & 0.0 & 18.1 & 0.3 & 10.4 & 78.1 \\
\hline Protein (3) meats. offal & $100 \mathrm{~g}$ & 110.0 & 146.6 & 21.8 & 5.7 & 96.8 & 0.4 & 0.0 & 14.9 & 226.6 \\
\hline raw/cooked vegetables & $75 \mathrm{~g}$ & 75.0 & 23.3 & 1.5 & 0.1 & 0.0 & 4.5 & 0.9 & 56.3 & 36.2 \\
\hline Carbohydrate: Rice & $100 \mathrm{~g}$ & 50.0 & 179.5 & 3.9 & 0.2 & 0.0 & 39.4 & 0.2 & 4.5 & 70.0 \\
\hline Carbohydrates (5) tub. plant root & - & 0.0 & 0.0 & 0.0 & 0.0 & 0.0 & 0.0 & 0.0 & 0.0 & 0.0 \\
\hline Candy or Dessert & $70 \mathrm{~g}$ & 70.0 & 197.7 & 2.2 & 1.8 & 0.0 & 44.9 & 0.1 & 56.9 & 48.6 \\
\hline Total Lunch & - & - & 705.2 & 33.8 & 8.5 & 96.8 & 130.0 & 2.5 & 179.6 & 504.1 \\
\hline \multicolumn{11}{|c|}{ Dinner } \\
\hline Fruit Juice & $200 \mathrm{cc}$ & 60.0 & 22.2 & 0.5 & 0.1 & 0.0 & 5.6 & 0.5 & 9.7 & 11.6 \\
\hline Soup or Cream & $200 \mathrm{cc}$ & 200.0 & - & - & - & - & - & - & - & - \\
\hline Carbohydrates (5) tub. plant root & $50 \mathrm{~g}$ & 50.0 & 58.3 & 0.7 & 0.1 & 0.0 & 14.5 & 0.5 & 5.9 & 20.5 \\
\hline Cooked Vegetables & $40 \mathrm{~g}$ & 40.0 & 14.4 & 1.0 & 0.1 & 0.0 & 2.7 & 0.5 & 30.7 & 24.1 \\
\hline Cereal Soup & $25 \mathrm{~g}$ & 25.0 & 25.0 & 2.8 & 0.5 & 0.0 & 18.1 & 0.3 & 10.4 & 78.1 \\
\hline Protein (3) meats. offal & $100 \mathrm{~g}$ & 110.0 & 146.6 & 21.8 & 5.7 & 96.8 & 0.4 & 0.0 & 14.9 & 226.6 \\
\hline raw/cooked Vegetables & $75 \mathrm{~g}$ & 75.0 & 23.3 & 1.5 & 0.1 & 0.0 & 4.5 & 0.9 & 56.3 & 36.2 \\
\hline Carbohydrate: Rice & - & 0.0 & 0.0 & 0.0 & 0.0 & 0.0 & 0.0 & 0.0 & 0.0 & 0.0 \\
\hline Carbohydrates (5) tub. Plant root & $100 \mathrm{~g}$ & 120.0 & 139.8 & 1.7 & 0.2 & 0.0 & 34.7 & 1.1 & 14.2 & 49.2 \\
\hline Candy or Dessert & $70 \mathrm{~g}$ & 70.0 & 197.7 & 2.2 & 1.8 & 0.0 & 44.9 & 0.1 & 56.9 & 48.6 \\
\hline
\end{tabular}

Table 2: Diet given to the study volunteers. 
Citation: Vargas M, Villarraga EA (2016) Bioequivalence Study of Two Formulations Containing Lurasidone 80 mg Tablets in Healthy Colombian Volunteers. J Bioequiv Availab 8: 220-223. doi:10.4172/jbb.1000299

(EMA) for drug assessment [7]. $\mathrm{AUC}_{\text {total }}$ was calculated by the sum of partial AUC: a) $\mathrm{AUC}_{0-\mathrm{t}}$, between zero time point and the last time point with detectable concentrations, calculated through the trapezoidal rule and guaranteeing the calculation of at least $80 \%$ of the AUC with the last sample, b) $\mathrm{AUC}_{\mathrm{t}-\infty}$, calculated as the $\mathrm{C} / \mathrm{K}$ ratio, where $\mathrm{C}$ is the last detectable concentration and $\mathrm{K}$ the slope obtained by linear regression from the points corresponding to the drug elimination phase through a linear regression of the natural logarithm of concentrations [8].

Bioavailability-adjusted elimination constant $(\mathrm{Ke})$, half-life $\left(\mathrm{t}^{1} / 2\right)$, clearance $(\mathrm{Cl})$ and mean residence time $(\mathrm{MRT})$ were calculated after performing the non-compartmental analysis. The results of pharmacokinetic variables are summarized in Table 3 with the Clarence, half-life, $\mathrm{C}_{\max }, \mathrm{AUC}_{0-\mathrm{t}}, \mathrm{AUC}_{0-\infty}, \mathrm{t}_{\max }$ values and the elimination rate $(\mathrm{Ke})$ of each one of the studied formulations.

Statistical analysis: An analysis of variance (ANOVA) was used to determine possible effects for each variation factor by sequence, period or subject. For this, F-test with a statistical significance level of $5 \%(\alpha=0.05)$ was used. Statistical comparison of transformed pharmacokinetic parameters of both formulations was performed using the statistical software WinNonlin version 5.3. The following Bioequivalence criterion was established in the protocol: The $90 \%$ confidence interval of Test $\mathrm{C}_{\max } /$ Reference $\mathrm{C}_{\max }$ and last Test AUC/last Reference, ratios that should be within the range $80-125 \%$ acceptability. In addition, the last AUC parameter should not be less than $80 \%$ of total AUC parameter.

Adverse events report: Adverse events were recorded according to INVIMA guidelines Provision No. (1067/08), which defines them as serious or not serious and then, according to its definition, as likely, potential or non-related with the study medication. Since the sample size does not have enough statistical power, cases are informed as received from the investigation unit only and without any statistical estimation.

\section{Results}

The study involved the participation of 24 healthy Colombian volunteers of both genders ( $50 \%$ women and $50 \%$ men) who completed both periods and were included in the pharmacokinetic and statistical analysis. Both treatments were well tolerated, with the presence of minor adverse events, the most reported adverse event was somnolence in $91 \%$ of volunteers who used the reference product and $100 \%$ of the volunteers who used the test product. Table 4 shows the averages of the pharmacokinetic parameters obtained from all volunteers (mean \pm SD) and confidence intervals of $90 \%$ of the pharmacokinetic parameters logarithmically transformed, analysis performed to determine bioequivalence between the test Lafrancol S.A. and Latuda produced Sunovion are shown in Table 5.

\section{Discussion}

The reduction in costs of cardiovascular pathologies treatment using multisource products is a desired aim by government and, accordingly, Bioequivalence studies allow suggesting the interchangeability of generic products versus reference products without repeating clinical trials in patients $[6,7]$.

WHOrecommendsin its guidelines for the Conduction of Comparative Bioavailability Studies to carry out in vivo testing in multisource products to assess one dose and a sudden increase of the medication in plasma concentration, which was evaluated in this study [9]. These findings are consistent with other studies, which assess the pharmacokinetics changes of Lurasidone when administered without food $[4,5]$.
The Pharmaceutical Equivalence Statement allowed qualifying the in vitro quality attributes of both formulations. These two periods, two sequences, crossover, single-dose design with healthy volunteers minimizes the variability and allows assessing the formulation effects. The analytical method used was selective, precise, accurate and robust. All 24 volunteers completed the study and did not exhibit adverse events with any of the formulations. The washout period was higher than the recommended 7 elimination half-lives and guaranteed the absence of carryover effect between periods.

The objective of this study was to assess the Bioequivalence of two Luirasidone $80 \mathrm{mg}$ formulations. Figure 1 shows the curves of the graphic representation of mean plasma concentration vs. time where similarity can be observed. Furthermore, the mean $\mathrm{AUC}_{0-\mathrm{t}}$ and $\mathrm{C}_{\max }$ were not significantly different and the $90 \%$ confidence intervals of ratios (Test/ Reference) to the mean criteria of $\mathrm{AUC}_{0-\mathrm{t}}$ and $\mathrm{C}_{\max }$ comply with the interval requested by the FDA and the EMA (Table 5) [7].

Our study was limited by the use of a design of a single dose, including women and healthy men, and the study was conducted only in the fasting state. Because the study was conducted in healthy volunteers, the results are not representative of a population of patients or those with significant medical conditions.

\section{Conclusions}

The Lurasidone formulation manufactured by Lafrancol S.A. (Test Product) and Sunovion manufactured by Latuda (Reference Product) has pharmacokinetic parameters that allow stating Bioequivalence between both formulations.

\begin{tabular}{|c|c|c|c|c|c|c|}
\hline Treatment & $\begin{array}{l}\text { Elimination } \\
\text { Rate }(1 / \mathrm{h})\end{array}$ & $\begin{array}{l}\text { Life } \\
\text { Mean } \\
\text { (h) }\end{array}$ & $t_{\text {max }}(h)$ & $\begin{array}{l}C_{\text {max }} \\
\text { (ng/ } \\
\mathrm{mL})\end{array}$ & $\begin{array}{c}A^{A U C} C_{0-t} \\
\left(h^{*} n g / m L\right)\end{array}$ & $\begin{array}{c}\text { AUC }_{0-\operatorname{lnf}} \\
\left(h^{*} \mathrm{ng} / \mathrm{mL}\right)\end{array}$ \\
\hline $\begin{array}{c}\text { Reference } \\
\text { Product }\end{array}$ & $\begin{array}{c}0.137 \pm \\
0.137\end{array}$ & $8.8 \pm 8.6$ & $\begin{array}{l}2.0 \pm \\
0.2\end{array}$ & $\begin{array}{c}71.5 \pm \\
10.6\end{array}$ & $\begin{array}{c}310.2 \pm \\
107.3\end{array}$ & $\begin{array}{c}360.1 \pm \\
133.7\end{array}$ \\
\hline $\begin{array}{c}\text { Test } \\
\text { Product }\end{array}$ & $\begin{array}{c}0.137 \pm \\
0.078\end{array}$ & $7.1 \pm 4.5$ & $\begin{array}{c}2.0 \pm \\
0.1\end{array}$ & $\begin{array}{c}71.2 \pm \\
8.6\end{array}$ & $\begin{array}{c}299.7 \pm \\
83.5\end{array}$ & $\begin{array}{c}351.9 \pm \\
110.2\end{array}$ \\
\hline
\end{tabular}

Table 3: Pharmocokinetic parameters of Lurasidone of test product (Lafrancol S.A.) and reference product (Latuda ${ }^{\circledR}$ ) followed by a single oral dose of $80 \mathrm{mg}$ on fasting state.

\begin{tabular}{|c|c|c|}
\hline \multicolumn{2}{|c|}{ Summary submitted by formulation studied RAM } \\
\hline RAM & Reference & Test \\
\hline Drowsiness & $91 \%$ & $100 \%$ \\
\hline Sickness & $48 \%$ & $52 \%$ \\
\hline Diarrhea & $0 \%$ & $4 \%$ \\
\hline Headache & $17 \%$ & $13 \%$ \\
\hline Abdominal Pain & $0 \%$ & $4 \%$ \\
\hline Dyskinesia & $4 \%$ & $0 \%$ \\
\hline Dizziness & $9 \%$ & $0 \%$ \\
\hline
\end{tabular}

Table 4: Consolidated adverse reactions presented.

\begin{tabular}{|c|c|c|c|c|}
\hline & Units & Ratio\% ref & \multicolumn{2}{|c|}{$\begin{array}{c}\text { Standard Cl 90\% (Test/ } \\
\text { Reference) }\end{array}$} \\
\hline Ln $\left(\mathrm{C}_{\text {max }}\right)$ & $\mathrm{ng} / \mathrm{mL}$ & 108.49 & 103.58 & 113.63 \\
\hline Ln $\left(\mathrm{AUC}_{0-\mathrm{t}}\right)$ & $\mathrm{h} . \mathrm{ng} / \mathrm{mL}$ & 104.46 & 97.96 & 111.39 \\
\hline Ln $\left(\mathrm{AUC}_{0-\infty}\right)$ & $\mathrm{h} . \mathrm{ng} / \mathrm{mL}$ & 104.57 & 98.32 & 111.21 \\
\hline Ln $\left(\mathrm{T}_{\text {max }}\right)$ & $\mathrm{h}$ & 98.6 & 89.86 & 108.2 \\
\hline
\end{tabular}

Table 5: $90 \%$ confidence intervals of logarithmically transformed pharmacokinetic parameters of two formulations containing Lurasidone (Test and reference products) after administration to healthy volunteers. 


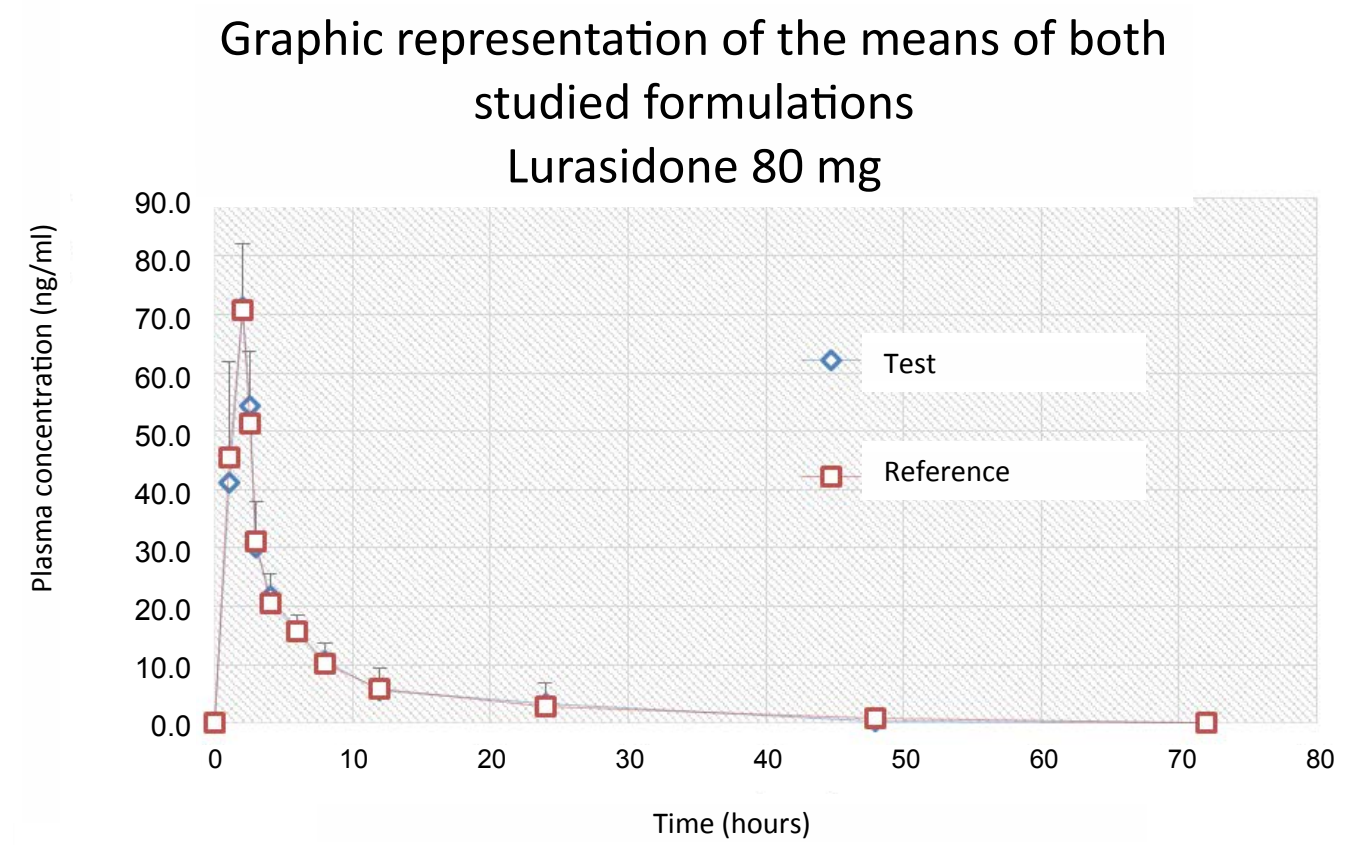

Figure 1: Bioavailability curve (Concentration vs. Time) obtained following a dose on fasting state of Lurasidone 80 mg of the test product (Lafrancol S.A.) and the reference product (Latuda ${ }^{\circledR}$ of Sunovion).

\section{References}

1. Fountoulakis KN, Gazouli M, Kelsoe J, Akiskal H (2015) The pharmacodynamic properties of lurasidone and their role in its antidepressant efficacy in bipolar disorder. European Neuropsychopharmacology 25: 335-342.

2. World Medical Association Declaration of Helsinki (2008) $59^{\text {th }}$ General Assembly Seoul, Korea.

3. www.fda.gov/Drugs/GuidanceCompliance Regulatory Information/Guidances.htm

4. Chae YJ, Koo TS, Lee KY (2012) A Sensitive and Selective LC-MS Method for the determination of lurasidone in rat plasma, bile, and urine. Chromatographia 75: 1117-1128.
5. Koo TS, Kim SJ, Lee J, Ha DJ, Baek M et al. (2011) Quantification of lurasidone, an atypical antipsychotic drug, in rat plasma with high performance liquid chromatography with tandem mass spectrometry. Biomed Chromatogr 25: $1389-1394$.

6. Food and Drugs Administration (2009) Guidance for industry Statistica Approaches to Establishing Bioequivalence.

7. The European Agency for the Evaluation of Medicinal Products EMA (2001) Committee for Proprietary Medicinal Products (CPMP) Note for guidance on the investigation of Bioavailability and Bioequivalence, London.

8. Perry R (2010) Perspectives on the bioequivalence and therapeutic equivalence of generic formulations: An overview of the landscape. Clin Ther 32: 1796-1797.

9. WHO (2006) Technical Report series, Fortieth Report, Geneva. 